\title{
The Epidemiology of Patellofemoral Pain in Majmaah, Saudi Arabia
}

\author{
Walaa S. Mohammad ${ }^{1,2^{*}}$ and Walaa M. Elsais ${ }^{3,4}$ \\ 'Department of Biomechanics, Faculty of Physical Therapy, Cairo University, Giza, Egypt; \\ walaa.sayed@pt.cu.edu.eg \\ 2Department of Physical Therapy, College of Applied Medical Sciences, Majmaah University, \\ Majmaah, Saudi Arabia \\ ${ }^{3}$ Centre for Health Sciences Research, University of Salford, Manchester, United Kingdom \\ ${ }^{4}$ Department of Physical Therapy, College of Allied Medical Sciences, Isra University, Amman, Jordan
}

\begin{abstract}
Patellofemoral Pain (PFP) is frequently described as clinical knee pain influencing adolescents and physically active adults; however, prevalence and risk factors in a large-scale population is not well established. This study aimed to investigate the prevalence of PFP in Majmaah, Saudi Arabia; and to interpret the influence of factors such as age, gender and BMI on the prevalence of PFP. Two hundred and forty-eight subjects including males and females were assessed in this study. A crosssectional study was performed in Majmaah Governorate, and surrounding cities, Saudi Arabia. The prevalence of PFP was considerably high among females $(72.3 \%)$, while it was $27.7 \%$ among males. Moreover, the age was a significant predictor for PFP [OR=1.04, 95\% CI-1.01-1.07], while the gender and BMI were not significant predictors. Based on these results, PFP is a commonly reported knee condition among adolescents. Apart from gender factor, overweight persons appear to be more liable to develop PFP. Moreover, increasing age is strongly associated with increasing risk of PFP.
\end{abstract}

Keywords: Majmaah, Patellofemoral Pain (PFP) Syndrome, Risk Factors

\section{Introduction}

Patellofemoral Pain (PFP) is an overuse injury of the knee that frequently affects adolescent and physically active adults, particularly in young women ${ }^{1,2}$. PFP commonly described as pain felt behind or around the patella which subsequently results in limitations of daily living activities $^{3}$. These symptoms aggravated by lengthysitting, crouching, kneeling, and stair negotiation ${ }^{4}$. Consequently, PFP could be worse to osteoarthritis of patellofemoral joint ${ }^{5,6}$. The causes of PFP are not clearly well-known, however, it may be associated to training load, lower extremity's pathomechanics, insufficient physical activity level, previous trauma, genetics, and psychsocial issues ${ }^{7}$. Although it has been reported that PFP is attributed to overuse and trauma ${ }^{8}$; the vast majority of PFP patients have no history of trauma ${ }^{5}$. Additionally, patellofemoral pain has been classified as a multifactorial condition'. It could result from the increased quadriceps angle (Q-angle), a disturbed activation pattern of vasti muscles $^{10,11}$, overuse of the patellofemoral joint or an increased level of activity ${ }^{12}$.

Understanding the contributing factors related to PFP could be of a great value in controlling and preventing such syndrome, however, the prevalence of PFP vary greatly in literature ${ }^{13}$. The incidence of PFP is predominantly documented in teenagers ${ }^{14}$. A previous study found that the PFP prevalence may be up to $40 \%{ }^{15}$. However, the majority of these PFP prevalence studies were limited to athletic population ${ }^{16,17}$, military personnel ${ }^{1}$, or school

${ }^{*}$ Author for correspondence 
children ${ }^{18}$. Thus far, a small number of researches have been conducted on general populations. The variations in the prevalence and risk factors for PFP could greatly attribute to variation in populations being investigated and lack of standard assessment ${ }^{15,19}$. Previous studies reported that the PFP is supposed to influence a various range of population, particularly adolescents; with higher incidence rates among females ${ }^{20,21}$.

Due to its high rate of incidence, prohibition of PFP should be considered. The prevention process includes monitoring the incidence rate and identification of causes linked to PFP. The PFP is a widespread knee problem which has been investigated in many countries. However, no study examined the prevalence of PFP in general Saudi population. The purposes of the present study were to explore the prevalence of PFP in the general Saudi residents and to analyse the influence of factors such as age, gender and BMI on the prevalence of PFP.

\section{Materials and Methods}

\subsection{Sample Characteristics}

A cross-sectional study was conducted to assess the prevalence and the risk factors of PFP among populations in Majmaah Governorate, and surrounding cities (Al Zulfi, Sudair), Saudi Arabia. The participants were divided into two groups; group 1 (PFP group) included participants who had anterior knee pain, group 2 included participants without anterior knee pain. Both groups had a clear history of hips, ankles, or feet injuries. Participants were excluded if they had any of the following conditions: history of injury or surgery of the lower extremity joints, history of arthritis, history of neurological or rheumatic conditions, or a history of low back pain or sciatica pain. Two hundred and forty-eight subjects including males and females were assessed. Before commencing the data collection, each participant read and signed a written informed consent statement approved by the Institutional Ethical Review Committee with approval number MUREC-Nov.25/COM-2020/10-5.

\subsection{Measures}

A self-report questionnaire (SNAPPS-Survey), designed by Dey et al. ${ }^{22}$ were used in the current study. The questionnaire was designed to distinguish between populations with and without PFP. The questionnaire was consisted of four sections. The finding of Dey et al., ${ }^{22}$ displayed high sensitivity and specificity for sections 1 , 2 and 4 . Therefore, based on scores from those sections, the data were collected. In section 1, the participants were asked if they experienced pain or serious issue in or around the knee in the past year. If the answer was "no," the questionnaire would be terminated and submitted, and those participants were assigned to the set of without PFP. The participant would continue answering the remaining two sections if he/she answered "yes". The total score of each participant was presented by estimating the summation of marks on sections 2 and 4 . A threshold mark of 6 or more was categorised into the group of with PFP. The participant with a score of less than 6 was considered as self-reported knee pain but not $\mathrm{PFP}^{21}$. Furthermore, the participant was assigned to set of with PFP if the pain was aggravated by a minimum of 2 tasks of the following activities: lengthy sitting, crouching, kneeling, running, ascending or descending stairs and hopping ${ }^{20}$.

\subsection{Statistical Analysis}

The prevalence and risk factors of PFP were investigated among male and female participants, and the data were analysed using Statistical Package for Social Sciences (version 25.0 for Windows; SPSS Inc., Chicago, IL). The potential risk factors were analysed to compare the groups using a Chi-square test, or T-Test, as applicable. A logistic regression analysis was executed to establish the effects of age, gender and BMI on the probability that participants have PFP. The level of significance will be set at $\mathrm{P}<0.05$ for all statistical tests.

\section{Results}

Two hundred forty-six responses were received to the study questionnaires. Participants who got a score of less than six were considered as self-reported knee pain and were excluded from the study. The remaining responses, 242 responses (184 women and 58 men), underwent further analysis.The mean age, height, mass and BMI of the participants were $27.67 \pm 11.00$ years, $161.31 \pm 8.00$ $\mathrm{cm}, 63.24 \pm 15.07 \mathrm{~kg}, 24.19 \pm 5.00 \mathrm{~kg} / \mathrm{m} 2$; respectively). Ninety-four of the participants had PFP (38.8\%), 68 of them were females and 26 were males (Table 1). The prevalence of PFP was considerably high among females (72.3\%), while it was $27.7 \%$ among males. To examine the correlation between gender (male as reference), age, and 
BMI and PFP, logistic regression analysis was executed. The results showed that age was a significant predictor for PFP, while the gender and BMI were not significant predictors (Table 2).

\section{Discussion}

This is the first study investigating the prevalence of PFP among Saudi residents. In the present study, a high prevalence for PFP was found in the community; about $39 \%$ of the participants reported PFP, with higher incidence among females compared to males $(72.3 \%$ vs. $27.7 \%)$. The findings of the present study show a higher prevalence compared to the previous investigations ${ }^{1,21,23,24}$.
The discrepancy in the prevalence between the results from the current study and those from previous studies may be contributed to differences in populations studied (e.g. athletes), unlike age group and diagnostic methods. Our results revealed a significant correlation between the gender and the prevalence of PFP, in which females had more potential in developing PFP. These findings supported the hypothesis that the prevalence of PFP would differ significantly between men and women. Several epidemiologic studies have documented a high incidence rate of PFP in women ${ }^{1,21,23,25}$, however they studied specific populations rather than general populations. This can be attributed to a number of biomechanical and anatomical influences that could maximise the incidence rate of PFP

Table 1. Demographic data for participants with and without PFP and factors associated with PFP

\begin{tabular}{|c|c|c|c|c|c|c|}
\hline \multirow[t]{2}{*}{ Variable } & \multicolumn{2}{|c|}{ Females $(n=184)$} & \multirow{2}{*}{ P value } & \multicolumn{2}{|c|}{ Males $(n=58)$} & \multirow{2}{*}{$P$ value } \\
\hline & $\begin{array}{l}\text { With PFP } \\
(\mathrm{n}=68)\end{array}$ & $\begin{array}{l}\text { Without PFP } \\
\quad(\mathrm{n}=116)\end{array}$ & & $\begin{array}{l}\text { With PFP } \\
(\mathrm{n}=26)\end{array}$ & $\begin{array}{l}\text { Without PFP } \\
\qquad(\mathrm{n}=32)\end{array}$ & \\
\hline Age, mean $(\mathrm{SD})$ year & $28.12(11.41)$ & $25.53(9.03)$ & $0.001^{*}$ & $40.23(14.37)$ & $24.31(5.38)$ & $0.001^{\star}$ \\
\hline \multicolumn{7}{|l|}{$\begin{array}{l}\text { Prevalence according to } \\
\text { Age group, } n(\%)\end{array}$} \\
\hline$<19$ & $14(20.6)$ & $12(10.3)$ & & 0 & $4(12.5)$ & \\
\hline $20-29$ & $32(47.1)$ & $74(63.8)$ & & $10(38.5)$ & $26(81.3)$ & \\
\hline 30-39 & $10(14.7)$ & $18(15.5)$ & & 0 & $2(6.3)$ & \\
\hline $40-49$ & $8(11.8)$ & $8(6.9)$ & & $8(30.8)$ & 0 & \\
\hline $50-59$ & $4(5.9)$ & $4(3.4)$ & & $6(23.1)$ & 0 & \\
\hline+60 & 0 & 0 & & $2(7.7)$ & 0 & \\
\hline Weight, mean (SD) kg & $60.88(11.88)$ & $59.28(14.99)$ & $0.000^{*}$ & $75.69(11.87)$ & $72.50(14.99)$ & $0.014^{*}$ \\
\hline Length, mean $(\mathrm{SD}) \mathrm{cm}$ & $157.21(5.05)$ & $158.95(6.04)$ & NS & $169.73(6.96)$ & $171.94(6.14)$ & $0.000^{*}$ \\
\hline BMI, mean (SD) kg/m² & $24.65(4.84)$ & $23.39(5.32)$ & $0.000^{*}$ & $26.40(4.25)$ & $24.36(4.23)$ & $0.000^{*}$ \\
\hline
\end{tabular}

Significant $(\mathrm{P}<0.05)$

NS $=$ Not significant, $p>0.05$

Table 2. Logistic regression analysis to detect the associated factors with the prevalence of PFP

\begin{tabular}{|c|c|c|c|}
\hline Risk factors & P & OR & $95 \%$ CI \\
\hline Gender & 0.098 & 0.46 & $0.187-1.153$ \\
\hline Age & $0.007^{*}$ & 1.04 & $1.011-1.072$ \\
\hline BMI & 0.178 & 1.59 & $0.810-3.123$ \\
\hline
\end{tabular}

Significant $(\mathrm{P}<0.05)$

$\mathrm{CI}=$ confidence interval; $\mathrm{OR}=$ odds ratio 
in women compared with men. These factors include the degree of Q-angle, dynamic frontal plane alignment, and muscle strength of the lower extremity ${ }^{1,25}$.

The most interesting findings of the current study was that the highest percentage of the PFP took place in the age group interval of 20-29 years (in both females and males), followed by the age group interval of 10-19 years (only in females with PFP). In the same context, Witvrouw, et al., ${ }^{26}$ and Callaghan, Selfe ${ }^{15}$ reported that the highest prevalence of PFP has been observed in the teenager of 12-17 years. This may be explained by the finding of Verbrugge ${ }^{27}$ who stated that notifying injuries or disorders at an early age are not acceptable from males, contrary to females who encouraged to take care of her body. The outcomes of this study demonstrated a significant association between age and PFP which in partial agreement with Glaviano, Kew, Hart, Saliba ${ }^{23}$ who reported that PFP is experienced by a wide age range with the highest percentage in the age group of 50-59 years and 10-19 years was the fourth-highest percentage. Based on these results, age group, particularly teenager, are important factor to be considered when investigating the PFP.

A number of anthropometric measurements have been examined to identify those at the greatest risk for developing PFP. The findings of the current study show that the weight and BMI were significantly correlated with the prevalence of PFP. This confirms the finding that being overweight was a risk factor of PFP. However, many studies suggested that height, weight and BMI did not impact pain intensity, or the function in patients with PFP and consequently did not considered as a significant risk factor ${ }^{25,28,29}$. These differences may be due to the previous literature that was limited to a specific gender, age group, and population. The findings of Hart, et al., ${ }^{30}$ supported the current study results, as the authors reported that higher $\mathrm{BMI}$ is associated with PFP, but not present in adolescents with PFP. A logistic regression analysis ascertains that age was correlated with the prevalence of PFP; however, gender and BMI were not associated. Our data show that increasing age by 1 year increased the PFP prevalence by $1.04 \%$. Although, many papers have been conducted to identify the influences affecting the prevalence of $\mathrm{PFP}^{1,26,31,32}$, there is no consensus in the literature about the factors contributing to PFP. This may be attributed to the multifactorial aetiology of the $\mathrm{PFP}^{25,31}$. Therefore, more research is needed to assess additional factors that may increase the risk of developing PFP.

\section{Conclusion}

The present research indicates that PFP is common in our study population, especially in adolescent and young adult females. Regardless gender, being overweight has been shown to be correlated with high prevalence of PFP. Probably because of its multifactorial etiology, the PFP was not associated with gender and BMI. Although, age was a significant predictor for PFP. Moreover, because of the high incidence of PFP, prevention should be considered. Therefore, more researches are required for further investigation of the factors linked to the prevalence of PFP.

\section{Conflict of Interest}

The authors declared no conflict of interest.

\section{References}

1. Boling M, Padua D, Marshall S, Guskiewicz K, Pyne S, Beutler A. Gender differences in the incidence and prevalence of patellofemoral pain syndrome. Scand J Med Sci Sports. 2010; 20(5):725-30. https://doi.org/10.1111/j.16000838.2009.00996.x PMid:19765240 PMCid:PMC2895959

2. WoodL, MullerS, Peat G. The epidemiologyof patellofemoral disorders in adulthood: a review of routine general practice morbidity recording. Prim Health Care Res Dev. 2011; 12(2):157-64. https://doi.org/10.1017/S1463423610000460 PMid:21457600

3. Al-Hakim W, Jaiswal PK, Khan W, Johnstone D. Suppl 2: The non-operative treatment of anterior knee pain. The Open Orthopaedics Journal. 2012; 6:320. https:// doi.org/10.2174/1874325001206010320 PMid:22896779 PMCid:PMC3415630

4. Cirkel J, Klaassen W, Kunst J, Aarns T, Plag E, Goudswaard A, et al. NHG-Standaard Niet-traumatische knieproblemen bij kinderen en adolescenten. In: NHG-Standaarden 2009. Springer. 2009:1145-53. https://doi.org/10.1007/97890-313-6614-9_73

5. Dye SF. The pathophysiology of patellofemoral pain: a tissue homeostasis perspective. Clin Orthop Relat Res. 2005; 436(436):100-10. https://doi.org/10.1097/01. blo.0000172303.74414.7d PMid:15995427

6. Thomas MJ, Wood L, Selfe J, Peat G. Anterior knee pain in younger adults as a precursor to subsequent patellofemoral osteoarthritis: a systematic review. BMC Musculoskeletal Disorders. 2010; 11(1):201. https://doi.org/10.1186/14712474-11-201 PMid:20828401 PMCid:PMC2944218 
7. Alrayani H. Understanding the biomechanical risk factors of Patellofemoral Pain (PFP) in military individuals: University of Salford; 2018.

8. Fulkerson JP, Arendt EA. Anterior knee pain in females. Clin Orthop Relat Res. 2000; 372(372):69-73. https://doi.org/10.1097/00003086-200003000-00009 PMid:10738416

9. Nascimento LR, Teixeira-Salmela LF, Souza RB, Resende RA. Hip and knee strengthening is more effective than knee strengthening alone for reducing pain and improving activity in individuals with patellofemoral pain: a systematic review with meta-analysis. Journal of Orthopaedic and Sports Physical Therapy. 2018; 48(1):19-31. https://doi. org/10.2519/jospt.2018.7365 PMid:29034800

10. Emami MJ, Ghahramani MH, Abdinejad F, Namazi H. Q-angle: An invaluable parameter for evaluation of anterior knee pain. Arch Iran Med 2007; 10(1).24-26

11. Chester R, Smith TO, Sweeting D, Dixon J, Wood S, Song F. The relative timing of VMO and VL in the aetiology of anterior knee pain: a systematic review and meta-analysis. BMC Musculoskelet Disord. 2008; 9(1):64. https://doi.org/10.1186/1471-2474-9-64 PMid:18452611 PMCid:PMC2386790

12. Fairbank J, Pynsent P, van Poortvliet JA, Phillips H. Mechanical factors in the incidence of knee pain in adolescents and young adults. The Journal of Bone and Joint Surgery British Volume. 1984; 66(5):685-93. https://doi. org/10.1302/0301-620X.66B5.6501361 PMid:6501361

13. Oakes JL, McCandless P, Selfe J. Exploration of the current evidence base for the incidence and prevalence of patellofemoral pain syndrome. Physical Therapy Reviews. 2009; 14(6):382-7. https://doi.org/10.1179/1083319 09X12488667117177

14. Rathleff MS, Skuldbøl SK, Rasch MN, Roos EM, Rasmussen S, Olesen JL. Care-seeking behaviour of adolescents with knee pain: a population-based study among 504 adolescents. BMC Musculoskeletal Disorders. 2013; 14(1):225. https://doi.org/10.1186/1471-2474-14-225 PMid:23899043 PMCid:PMC3729825

15. Callaghan MJ, Selfe J. Has the incidence or prevalence of patellofemoral pain in the general population in the United Kingdom been properly evaluated? Physical Therapyin Sport. 2007; 8(1):37-43. https://doi.org/10.1016/j. ptsp.2006.07.001

16. Clarsen B, Krosshaug T, Bahr R. Overuse injuries in professional road cyclists. The American Journal of Sports Medicine. 2010; 38(12):2494-501. https://doi. org/10.1177/0363546510376816 PMid:20847225

17. Nejati P, Forogh B, Moeineddin R, Baradaran HR, Nejati M. Patellofemoral painsyndrome in Iranian female athletes. Acta Medica Iranica. 2011; 49(3):169-72.
18. RathleffMS, RoosEM, OlesenJ, Rasmussen S.Exerciseduring school hours when added to patient education improves outcome for 2 years in adolescent patellofemoral pain: A cluster randomised trial. Br J Sports Med. 2015; 49(6):40612 https://doi.org/10.1136/bjsports-2014-093929 PMid:25388552

19. Crossley K, Bennell K, Green S, Cowan S, McConnell J. Physical therapy for patellofemoral pain: a randomized, double-blinded, placebo-controlled trial. Am J Sports Med. 2002; 30(6):857-65. https://doi.org/10.1177/036354650203 00061701 PMid:12435653

20. Smith BE, Selfe J, Thacker D, Hendrick P, Bateman M, Moffatt F, et al. Incidence and prevalence of patellofemoral pain: A systematic review and meta-analysis. PLoS One. 2018; 13(1):e0190892. https://doi.org/10.1371/journal. pone.0190892 PMid:29324820 PMCid:PMC5764329

21. Xu X, Yao C, Wu R, Yan W, Yao Y, Song K, et al. Prevalence of patellofemoral pain and knee pain in the general population of Chinese young adults: a community-based questionnaire survey. BMC Musculoskelet Disord. 2018; 19(1):165. https://doi.org/10.1186/s12891-018-2083-x PMid:29793456 PMCid:PMC5968546

22. Dey P, Callaghan M, Cook N, Sephton R, Sutton C, Hough $\mathrm{E}$, et al. A questionnaire toidentify patellofemoral pain in the community: an exploration of measurement properties. BMC Musculoskelet Disord. 2016; 17(1):237. https:// doi.org/10.1186/s12891-016-1097-5 PMCid:PMC4886395

23. Glaviano NR, Kew M, Hart JM, Saliba S. Demographic and Epidemiological Trends in Patellofemoral Pain. Int J Sports Phys Ther. 2015; 10(3):281-90.

24. Althunyan AK, Darwish MA, Wahab MMA. Knee problems and its associated factors among active cyclists in Eastern Province, Saudi Arabia. Journal of Family and Community Medicine. 2017; 24(1):23. https://doi.org/10.4103/22308229.197178 PMid:28163572 PMCid:PMC5248430

25. Rothermich MA, Glaviano NR, Li J, Hart JM. Patellofemoral pain: Epidemiology, pathophysiology, and treatment options. Clin Sports Med. 2015; 34(2):313-27. https://doi. org/10.1016/j.csm.2014.12.011 PMid:25818716

26. Witvrouw E, Callaghan MJ, Stefanik JJ, Noehren B, BazettJones DM, Willson JD, et al. Patellofemoral pain: Consensus statement from the 3rd International Patellofemoral Pain Research Retreat held in Vancouver, September 2013. Br J Sports Med. 2014; 48(6):411-14. https://doi.org/10.1136/ bjsports-2014-093450 PMid:24569145

27. Verbrugge LM. Gender and health: An update on hypotheses and evidence. J Health Soc Behav. 1985; 26(3):156-82. https://doi.org/10.2307/2136750 PMid:3905939

28. Arrebola LS, Carvalho RTd, Lima VCdO, Percivale KAN, Oliveira VGCd, Pinfildi CE. Influence of body mass index on 
patellofemoral pain. Fisioterapia em Movimento. 2020; 33. https://doi.org/10.1590/1980-5918.033.ao09

29. Fok LA, Schache AG, Crossley KM, Lin YC, Pandy MG. Patellofemoral joint loading duringstair ambulation in people with patellofemoral osteoarthritis. Arthritis Rheum. 2013; 65(8):2059-69. https://doi.org/10.1002/art.38025 PMid:23740512

30. Hart HF, Barton CJ, Khan KM, Riel H, Crossley KM. Is body mass index associated with patellofemoral pain and patellofemoral osteoarthritis? A systematic review and meta-regression and analysis. British Journal of Sports Medicine. 2017; 51(10):781-790. https://doi.org/10.1136/ bjsports-2016-096768 PMid:27927675
31. Davis IS, Powers C. Patellofemoral pain syndrome: proximal, distal, and local factors-international research retreat, April 30-may 2, 2009, Baltimore, Maryland. Journal of Orthopaedic and Sports Physical Therapy. 2010; 40(3):A1-A48. https://doi.org/10.2519/jospt.2010.0302 PMid:20195028

32. Thomee R, Augustsson J, Karlsson J. Patellofemoral pain syndrome: A review of current issues. Sports Med. 1999; 28(4):245-62. https://doi.org/10.2165/00007256199928040-00003 PMid:10565551 